\title{
Overall and disease-specific survival outcomes following primary surgery for oral squamous cell carcinoma: analysis of consecutive 67 patients
}

\author{
Yookyeong Carolyn Sim ${ }^{1, *}$, Jong-Hyun Hwang ${ }^{2, *}$, Kang-Min Ahn ${ }^{2}$ \\ ${ }^{I}$ School of Medicine, Ewha Womans University, \\ ${ }^{2}$ Department of Oral and Maxillofacial Surgery, University of Ulsan College of Medicine, Asan Medical Center, Seoul, Korea
}

\begin{abstract}
J Korean Assoc Oral Maxillofac Surg 2019;45:83-90)
Objectives: This study evaluated the predictive factors for survival of patients with oral squamous cell carcinoma (OSCC) and investigated the overall and disease-specific survival (DSS) outcomes.

Materials and Methods: A total of 67 consecutive patients who underwent surgery for OSCC from January 2006 to November 2014 were included in this study. Patients were classified according to age, sex, pTNM stages, primary sites, smoking and alcohol drinking habits, depth of invasion, perineural and lymphovascular invasion, cell differentiation and postoperative radiotherapy. Kaplan-Meier methods were used to estimate the survival categorized by patient groups. Cox regression methods were used to investigate the main independent predictors of survival.

Results: Nineteen patients died of OSCC during follow-up periods. Another five patients died of other diseases including lung adenocarcinoma ( $\mathrm{n}=1$ ), cerebral infarction $(n=1)$, general weakness $(n=2)$, and pneumonia $(n=1)$. The tongue $(n=16)$ was the most common site for primary origin, followed by buccal mucosa $(n=15)$, mandibular gingiva $(n=15)$, maxillary gingiva $(n=9)$, floor of mouth $(n=9)$, retromolar trigone $(n=2)$, and palate $(n=1)$. Eleven patients had pTNM stage I disease, followed by stage II $(n=22)$ and stage IV $(n=34)$. No patients had pTNM stage III disease in this study. The overall survival of all patients was $64.2 \%$ and the DSS was $71.6 \%$. DSS of patients with stage I and II disease was $100 \%$. Stepwise Cox regression showed the two predictors for DSS were pTNM stage $(P<0.0001$, odds ratio $=19.633)$ and presence of metastatic lymph nodes $(P=0.0004$, odds ratio $=0.1039)$.

Conclusion: OSCC has been associated with poor prognosis; however, there were improved survival outcomes compared with past studies. Advanced-stage disease and presence of metastatic lymph nodes were associated with poorer survival compared with early-stage OSCC and absence of neck node metastasis. Stage I and II OSCC were associated with excellent survival results in this study.
\end{abstract}

Key words: Head and neck neoplasm, Survival, Lymphatic metastasis, Neoplasm staging

[paper submitted 2018. 2. 25 / revised 2018. 3. 16 / accepted 2018. 3. 22]

\section{Introduction}

Oral squamous cell carcinoma (OSCC) is a common malignancy worldwide, with regional variations in incidence and mortality ${ }^{1-3}$. The most common risk factors associated with OSCC are tobacco and alcohol abuse ${ }^{4}$; however, the incidence

\footnotetext{
Kang-Min Ahn

Department of Oral and Maxillofacial Surgery, University of Ulsan College of Medicine, Asan Medical Center, 88 Olympic-ro 43-gil, Songpa-gu, Seoul 05505, Korea

TEL: +82-2-3010-5901 FAX: +82-2-3010-6967

E-mail:ahnkangmin@hanmail.net

ORCID: https://orcid.org/0000-0003-1215-5643

*These authors contributed equally to this work as first authors.

(a) This is an open-access article distributed under the terms of the Creative Commons Attribution Non-Commercial License (http://creativecommons.org/ licenses/by-nc/4.0/), which permits unrestricted non-commercial use, distribution, and reproduction in any medium, provided the original work is properly cited. Copyright (O) 2019 The Korean Association of Oral and Maxillofacial Surgeons. All rights reserved.
}

in younger than 40 years without tobacco and alcohol abuse has increased ${ }^{5}$. Survival outcomes of OSCC have improved over the last 20 years, but the prognosis is still relatively unfavorable, with 5-year overall survival (OS) and disease-free survival estimated to be $47 \%$ and $74 \%^{6-8}$. Prognosis is thought to be influenced by factors related to the host, surgeon, and tumor. Establishing the interaction between these factors and patient prognosis is important. The most well-known critical factors associated with survival are disease stage at initial diagnosis, neck metastasis, invasiveness of cancer cells, and tumor thickness ${ }^{5,6,9-18}$. If regional metastases have occurred, the 5-year survival of OSCC is halved; therefore, the single most important clinical predictor in determining survival is the existence of clinically positive lymph nodes ${ }^{9}$. Other clinical and histopathologic prognostic factors include the size of the primary tumor, site, grade of cell differentiation, depth of invasion, biologic tumor markers, perineural invasion, 
distance between the patient's home and the hospital, and patient compliance ${ }^{6,9-18}$. Also, there is some evidence that the presence of tumors in the oral cavity can affect the outcome ${ }^{19}$. Surgical experience and a well-coordinated team approach with a medical oncologist and radiotherapist are also key factors for successful results. However, it is difficult to measure the skillfulness of the surgeon and the medical oncologist.

The main purpose of this article is to report the OS and disease-specific survival (DSS) of a consecutive series of patients presenting with oral cancer from 2006 to 2014 in the Department of Oral and Maxillofacial Surgery at Asan Medical Center (Seoul, Korea). We relate survival to clinical and pathologic factors including TNM stage, tumor site, tumor thickness, smoking and alcohol drinking habits, invasion of nerve and lymphovascular tissues, cell differentiation, and postoperative radiotherapy.

\section{Materials and Methods}

\section{Patients}

The data in this study reflect the survival outcomes of primary OSCC. The patients underwent oral and maxillofacial surgery by a single surgeon. The patients for this study were chosen based on strict inclusion and exclusion criteria.(Table 1) This cohort study comprised 216 patients who had been treated between January 2006 and November 2014 for oral cavity cancers including SCC, salivary gland cancer, melanoma and sarcoma. A total of 67 patients satisfied the inclusion criteria. No patients dropped out during the observation periods. Patients with primary OSCC, resectable OSCC or a single primary site were included. Patients presenting with unresectable OSCC $(n=26)$ or patients not eligible for general

Table 1. Inclusion and exclusion criteria for the study

\begin{tabular}{ll}
\hline \multicolumn{1}{c}{ Inclusion criteria } & \multicolumn{1}{c}{ Exclusion criteria } \\
\hline Primary OSCC & Referred patients after recurrence \\
Single site & Referred patients after neoadjuvant \\
Resectable OSCC & chemoradiotherapy \\
& Unresectable OSCC \\
& Not acceptable for general anesthesia \\
& Multiple primary OSCC \\
& Oral cavity cancer other than OSCC \\
& Presence of distant metastasis at initial \\
& work-up \\
& Refusal of surgical treatment \\
& Primary intra-osseous SCC \\
\hline
\end{tabular}

(OSCC: oral squamous cell carcinoma, SCC: squamous cell carcinoma) Yookyeong Carolyn Sim et al: Overall and disease-specific survival outcomes following primary surgery for oral squamous cell carcinoma: analysis of consecutive 67 patients. $J$ Korean Assoc Oral Maxillofac Surg 2019 anesthesia $(n=4)$ were excluded and transferred to the Departments of Oncology or Therapeutic Radiology for palliative treatment. Patients who were referred after neoadjuvant chemotherapy were also excluded $(n=2)$, as were referred patients with recurrent mass or multiple primary OSCC $(n=3)$. Although primary intraosseous squamous cell carcinoma (PIOS) has similar histopathologic characteristics to OSCC, patients with PIOS ( $n=2)$ were also excluded from this study: unlike OSCC, which basically originates from oral mucosa, PIOS originates from bone. Other exclusion criteria were oral cavity cancers other than OSCC, including osteosarcoma $(n=5)$, metastatic cancer from another organ $(n=37)$, salivary gland cancer $(n=57)$, and presence of distant metastasis $(n=2)$ at first visit. Patients who refused surgical treatment $(n=11)$ were also excluded.

Patients were classified according to sex, stage, primary sites, histologic grade, depth of invasion, pathologic lymph node status, radiotherapy, survival, and cause of death. The ages of the patients ranged from 20 to 84 years, with a mean age of $61.3 \pm 13.2$ years. There were 45 men $(67.2 \%)$ and 22 women (32.8\%). The Institutional Review Board from Asan Medical Center issued an exemption from approval to this study, because we collected existing data in such a manner that the subjects could not be identified.

\section{Treatment protocol}

Our department advocated radical primary surgery with free flap reconstruction where indicated in the management of oral cavity cancer. Surgery was performed with intention to cure by resection with a 1 to $1.5 \mathrm{~cm}$ safety margin. The procedure consisted of mass excision and/or neck dissection in the primary site. Neck dissection was performed when the risk of occult metastasis was higher than $15 \%$ or when manual examination and magnetic resonance imaging showed positive neck metastasis. Patients with N0 disease who required free flap reconstruction also underwent selective neck dissection of level I, II, and III. A frozen biopsy was performed during the surgery at 8 or more sites. A close or positive margin was treated by further resection. Additional frozen biopsies were taken until a negative margin was confirmed. At the time of mass excision, reconstruction using microvascular free flaps was also performed by the same surgeon. Free flap methods included radial forearm flap, fibular free flap, and latissimus dorsi free flap ${ }^{20}$. Postoperative radiotherapy was performed for patients with biopsy results of positive or close resection margin (less than $5 \mathrm{~mm}$ ) and pathologic results of 
positive neck metastasis.

\section{Statistical methods}

Survival time was calculated in months, from time of surgery to date last known alive by follow-up or telephone check-up, or date of death using a right censoring method. Cause of death was classified as either disease specific or from other causes for calculation of the DSS or OS rate. The $\chi^{2}$ test with Yates' correction was used to compare the proportions. The Kaplan-Meier algorithm was used to estimate OS and DSS. The significant difference between survival curves, when grouped according to all specific explanatory variables, was tested using the log-rank test.

Sex, age (younger than 50 vs 50 and older), stages (stage I, II vs stage IV), primary sites, histologic grades (well vs moderately vs poorly differentiated), depth of invasion (under vs over $5 \mathrm{~mm}$ ) and pathologic lymph node status (positive vs negative) were analyzed to identify predictive factors for survival. The Cox proportional hazards model with timeconstant covariate model was used to perform a multivariate analysis of these factors. Likelihood-ratio statistics based on the conditional parameter estimate methods of forward selection were used for analysis. The level of significance was set as $P<0.05$. Statistical analyses were carried out using the IBM SPSS for Windows (ver. 21.0; IBM Corp., Armonk, NY, USA).

\section{Results}

A total of 67 patients had primary surgery under general anesthesia, and 19 patients (28.4\%) received postoperative radiotherapy. The OS was $64.2 \%$ (43/67), while the DSS was 71.6\% (48/67).(Fig. 1) Patient characteristics associated with OS and DSS are listed in Table 2. A total of 24 patients died during the follow-up period. Among them, 19 patients died of OSCC. The causes of death were local recurrence $(n=7)$, loco-regional recurrence $(\mathrm{n}=11)$, and distant metastasis to lung $(\mathrm{n}=1)$. Five patients died of other diseases: lung adenocarcinoma $(n=1)$, cerebral infarction $(n=1)$, general weakness due to old age $(n=2)$, and pneumonia $(n=1)$.

The follow-up periods for the 67 patients ranged from 3 to 145 months, with a mean of $60.5 \pm 38.6$ months. The average survival periods of the survivors and the deceased were 21.6 \pm 16.7 months (range, $39-145$ months) versus $21.6 \pm 16.7$ months (range, 3-60 months). The average survival periods of the 19 patients who died of OSCC ranged from 3 to 56 months with a mean of $18.3 \pm 14.4$ months.

Age (younger than 50 vs 50 and older) and sex did not show any significant difference in OS and DSS. There were neither smokers nor heavy drinkers in the female group. Smoking and alcohol drinking also were not related with significant differences of OS and DSS.

Tongue $(n=16)$ was the most common site for primary origin, followed by buccal mucosa $(n=15)$, mandibular gingiva $(n=15)$, maxillary gingiva $(n=9)$, floor of mouth $(n=9)$, retromolar trigone $(\mathrm{n}=2)$, and palate $(\mathrm{n}=1)$. The deaths associated with each site were 3 patients with tongue, 5 patients with buccal mucosa, 5 patients with mandibular gingiva, three patients with maxillary gingiva, two patients with floor of mouth, and one patient with retromolar trigone. The primary sites were not significantly associated with the OS $(P=0.3928)$ and DSS $(P=0.8978)$.

Fifty-seven patients $(85.1 \%)$ underwent neck dissection simultaneous with primary resection. Ten patients did not receive neck dissection during the primary operation because of maxillary OSCC with N0 neck $(n=4)$ and small primary lesions $(n=6)$. However, four patients died of local recurrences $(n=2)$, loco-regional recurrence $(n=1)$, and second primary lesion $(n=1)$. Neck dissection was not significantly associated with OS and DSS.

Eleven patients had pTNM stage I disease, followed by stage II $(n=22)$ and stage IV $(n=34)$. There were no patients with stage III disease in our study. N1 category disease was found in six patients, but the primary lesion invaded the adjacent muscles in four patients and the maxillary and the mandibular bone in two patients. Therefore, all patients with N1

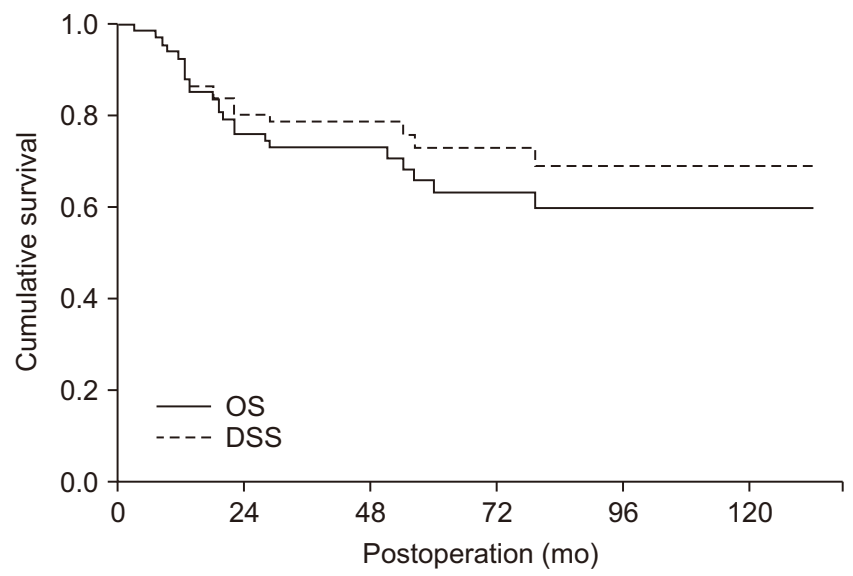

Fig. 1. Overall survival (OS) and disease-specific survival (DSS) of 67 patients with oral squamous cell carcinoma.

Yookyeong Carolyn Sim et al: Overall and disease-specific survival outcomes following primary surgery for oral squamous cell carcinoma: analysis of consecutive 67 patients. $J$ Korean Assoc Oral Maxillofac Surg 2019 
Table 2. Survival analysis for 67 patients with oral squamous cell carcinoma

\begin{tabular}{|c|c|c|c|c|c|c|c|c|c|c|c|c|}
\hline Factor & & n (\%) & DSD & DSS (\%) & $\operatorname{DSD}(\%)$ & $P$-value & Odds & OD & OS (\%) & OD (\%) & $P$-value & Odds \\
\hline \multirow[t]{3}{*}{ Age (yr) } & & & & & & 0.9304 & 0.9375 & & & & 0.7863 & 1.217 \\
\hline & $<50$ & $11(16.4)$ & 3 & 72.7 & 27.3 & & & 3 & 72.7 & 27.3 & & \\
\hline & $\geq 50$ & $56(83.6)$ & 16 & 71.4 & 28.6 & & & 21 & 62.5 & 37.5 & & \\
\hline \multirow{3}{*}{ Sex } & & & & & & 0.4667 & 0.5662 & & & & 0.3796 & 1.845 \\
\hline & Male & $45(67.2)$ & 11 & 75.6 & 24.4 & & & 14 & 68.9 & 31.1 & & \\
\hline & Female & $22(32.8)$ & 8 & 63.6 & 36.4 & & & 10 & 54.5 & 45.5 & & \\
\hline \multirow[t]{3}{*}{ Tobacco } & & & & & & 0.7552 & 1.3750 & & & & 0.6234 & 0.6818 \\
\hline & Yes & $35(52.2)$ & 11 & 68.6 & 31.4 & & & 14 & 60.0 & 40.0 & & \\
\hline & No & $32(47.8)$ & 8 & 75.0 & 25.0 & & & 10 & 68.8 & 31.3 & & \\
\hline \multirow[t]{3}{*}{ Alcohol } & & & & & & 0.6272 & 0.6462 & & & & 0.6234 & 0.6818 \\
\hline & Non or light & $41(61.2)$ & 13 & 68.3 & 31.7 & & & 14 & 65.9 & 34.1 & & \\
\hline & Heavy & $26(38.8)$ & 6 & 76.9 & 23.1 & & & 10 & 61.5 & 38.5 & & \\
\hline \multirow[t]{3}{*}{ TNM } & & & & & & $<0.0001 *$ & 19.6330 & & & & $<0.0001 *$ & 22.143 \\
\hline & Stage I-II & 33 (49.3) & 0 & 100.0 & 0.0 & & & 2 & 93.9 & 6.1 & & \\
\hline & Stage III-IV & $34(50.7)$ & 17 & 50.0 & 50.0 & & & 20 & 41.2 & 58.8 & & \\
\hline \multirow[t]{3}{*}{$\mathrm{LN}$} & & & & & & $0.0004 *$ & 0.1039 & & & & $0.0047^{*}$ & 0.162 \\
\hline & Positive & $17(25.4)$ & 11 & 35.3 & 64.7 & & & 12 & 29.4 & 70.6 & & \\
\hline & Negative & $50(74.6)$ & 8 & 84.0 & 16.0 & & & 14 & 72.0 & 28.0 & & \\
\hline \multirow[t]{3}{*}{ DOI } & & & & & & 0.0587 & 3.7500 & & & & 0.0682 & 3.143 \\
\hline & $<5$ & $28(41.8)$ & 4 & 85.7 & 14.3 & & & 6 & 78.6 & 21.4 & & \\
\hline & $\geq 5$ & $39(58.2)$ & 15 & 61.5 & 38.5 & & & 18 & 53.8 & 46.2 & & \\
\hline \multirow[t]{3}{*}{ PNI } & & & & & & 0.8449 & 0.7826 & & & & 0.9267 & 1.122 \\
\hline & Yes & $3(4.5)$ & 1 & 66.7 & 33.3 & & & 1 & 66.7 & 33.3 & & \\
\hline & No & $64(95.5)$ & 18 & 71.9 & 28.1 & & & 23 & 64.1 & 35.9 & & \\
\hline \multirow[t]{3}{*}{ LVI } & & & & & & 0.3061 & 0.2519 & & & & 0.8973 & 0.8846 \\
\hline & Yes & $5(7.5)$ & 2 & 60.0 & 40.0 & & & 2 & 60.0 & 40.0 & & \\
\hline & No & $62(92.5)$ & 17 & 72.6 & 27.4 & & & 23 & 62.9 & 37.1 & & \\
\hline \multirow[t]{3}{*}{ ND } & & & & & & 0.6134 & 1.8670 & & & & 0.7651 & 1.233 \\
\hline & Yes & 57 (85.1) & 15 & 73.7 & 26.3 & & & 20 & 64.9 & 35.1 & & \\
\hline & No & $10(14.9)$ & 4 & 60.0 & 40.0 & & & 4 & 60.0 & 40.0 & & \\
\hline \multirow[t]{3}{*}{ RT } & & & & & & 0.0928 & 0.3706 & & & & 0.1278 & 0.3706 \\
\hline & Yes & $19(28.4)$ & 10 & 47.4 & 52.6 & & & 10 & 47.4 & 52.6 & & \\
\hline & No & 48 (71.6) & 9 & 81.3 & 18.8 & & & 14 & 70.8 & 29.2 & & \\
\hline \multirow{8}{*}{ Site } & & & & & & 0.8978 & & & & & 0.3928 & \\
\hline & Tongue & $16(23.9)$ & 3 & 81.3 & 18.8 & & & 3 & 81.3 & 18.8 & & \\
\hline & $\begin{array}{l}\text { Buccal } \\
\text { mucosa }\end{array}$ & $15(22.4)$ & 5 & 66.7 & 33.3 & & & 7 & 53.3 & 46.7 & & \\
\hline & FOM & $9(13.4)$ & 2 & 77.8 & 22.2 & & & 2 & 77.8 & 22.2 & & \\
\hline & Mn. gingiva & $15(22.4)$ & 5 & 66.7 & 33.3 & & & 8 & 46.7 & 53.3 & & \\
\hline & Mx. gingiva & $9(13.4)$ & 3 & 66.7 & 33.3 & & & 3 & 66.7 & 33.3 & & \\
\hline & RMT & $2(3.0)$ & 1 & 50.0 & 50.0 & & & 1 & 50.0 & 50.0 & & \\
\hline & Soft palate & $1(1.5)$ & 0 & 100.0 & 0.0 & & & 0 & 100.0 & 0.0 & & \\
\hline
\end{tabular}

(DSD: disease-specific death, DSS: disease-specific survival, OD: overall death, OS: overall survival, LN: lymph node metastasis, DOI: depth of invasion, PNI: perineural invasion, LVI: lymphovascular invasion, ND: neck dissection, RT: radiotherapy, FOM: floor of mouth, Mn.: mandible, Mx.: maxilla, RMT: retromolar trigone)

$* P<0.05$.

Yookyeong Carolyn Sim et al: Overall and disease-specific survival outcomes following primary surgery for oral squamous cell carcinoma: analysis of consecutive 67 patients. J Korean Assoc Oral Maxillofac Surg 2019

category disease were classified as having stage IV disease.

Neck node metastasis was found in 17 patients. For lymph node status, pathologic examination revealed that $59 \%$ were N0 grade, $13.9 \%$ were N1 grade and $4.2 \%$ were N2b grade. Lymph node size of over $6 \mathrm{~cm}$ was not found in this study. The pathologic report after mass excision and neck dissection revealed that $41.7 \%$ were stage II and $45.8 \%$ were stage IV. In stepwise Cox regression, the two predictors selected for DSS were pTNM stage $(P<0.0001$, odds ratio=19.633) (Fig. $2)$ and presence of metastatic lymph node $(P=0.0004$, odds ratio $=0.1039)$.(Fig. 3)
Through histopathologic examination, 67 patients' histologic grades were classified as well, moderately, and poorly differentiated. Well differentiated grades were found in $62.5 \%$ and moderately differentiated grades were found in $29.2 \%$. Only one patient was revealed as having poorly differentiated disease. It was difficult to estimate OS and DSS related to histologic grade because few patients had poorly differentiated disease, but histologic grade (well and moderate differentiation) did not show significant associations with OS and DSS. 


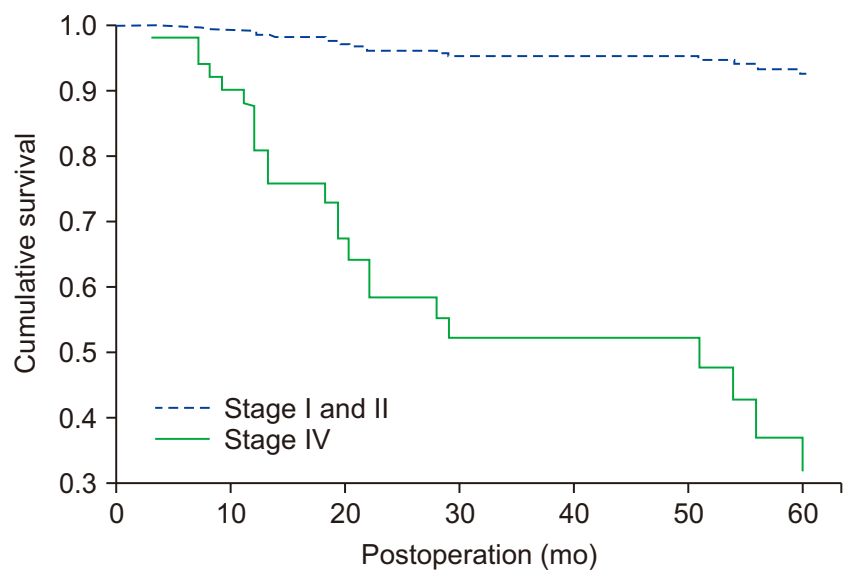

Fig. 2. Comparison of the disease-specific survival of neck node positive and negative groups.

Yookyeong Carolyn Sim et al: Overall and disease-specific survival outcomes following primary surgery for oral squamous cell carcinoma: analysis of consecutive 67 patients. $J$ Korean Assoc Oral Maxillofac Surg 2019

\section{Discussion}

This is the first article from our department to concentrate on the OS and DSS with OSCC. The study was designed in 2006, and no patients dropped out. Despite the advancement of cancer therapy, the survival rate for OSCC has not significantly changed over the past 20 years. Since the 1970s, survival rates for oral cancer have remained constant whilst the incidence has increased among the younger and non-smoking populations ${ }^{21}$. In several recent studies, the 5 -year survival rate was $47 \%$ to $58 \% \%^{22,23}$. In comparison, OS and DSS in our study were $64.2 \%$ and DSS $71.6 \%$, which were quite favorable results. DSS for patients with stage I and II disease was $100 \%$.

Tumor behavior in patients is highly variable and depends on several host and primary tumor factors. Predicting these behaviors is important to determine the prognosis of the patient and select the proper optimal treatment. Oral and maxillofacial departments at relatively few institutions have reported the survival data of their patients with OSCC, because diligence is required in collecting accurate data from a relatively small number of patients. With a history of 29 years, our department has used a computer system to collect data since 2006 on patients with oral cancer. All the data were organized for statistical analysis regarding demographic characteristics, tumor characteristics, survival, and comorbidity.

Previous studies have reported on risk factors that are associated with the survival rate. Such factors include clinical aspects (patch, plaque, papule, nodule, and ulcer), size ( $\mathrm{T}$ stage), regional metastasis ( $\mathrm{N}$ stage), clinical stage, and treat-

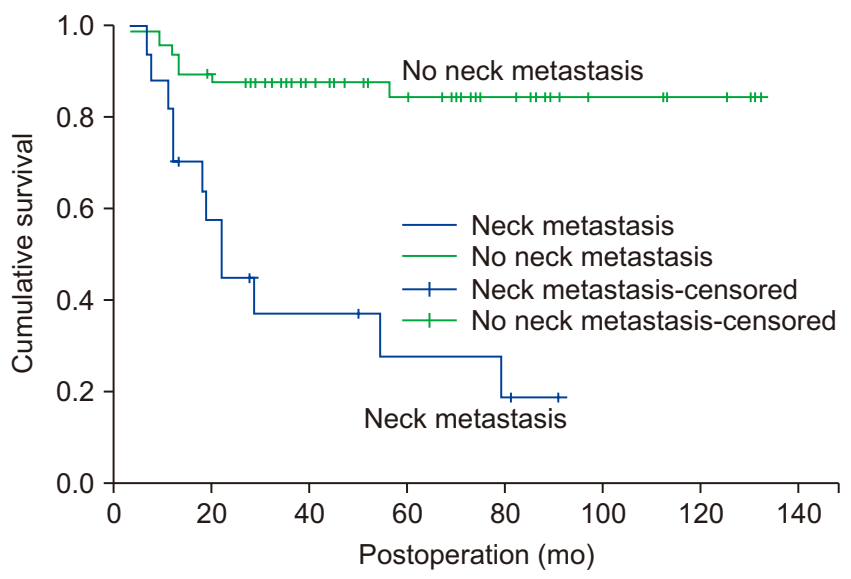

Fig. 3. Disease-specific survival for 67 patients with oral squamous cell carcinoma by pTNM stage.

Yookyeong Carolyn Sim et al: Overall and disease-specific survival outcomes following primary surgery for oral squamous cell carcinoma: analysis of consecutive 67 patients. $J$ Korean Assoc Oral Maxillofac Surg 2019

ment (surgical, radiotherapy, adjuvant, or no treatment) ${ }^{8}$. Our results did not show any significant difference of survival with age, sex, primary sites, smoking and drinking habits, differentiation, depth of invasion, and postoperative radiotherapy. Two factors that were related to OS and DSS were pTNM stage and presence of neck node metastasis. Studies have shown that patients with advanced-stage disease have lower survival ${ }^{3}$. In fact, a recent study states that the most important clinical predictor of survival remains TNM stage at the time of diagnosis ${ }^{8}$. The survival rate is lower in poorgrade or advanced TNM stages ${ }^{20,24-26}$. In our study, patients with stage I and II disease showed DSS of $100 \%$. It could be concluded that early-stage OSCC is curable, and therefore early detection is critical. The importance of routine dental check-ups should be emphasized. Our sample included no patients with stage III disease, because we categorized our patients based on pathologic staging, not clinical staging. It was due to shrinkage (30\%-40\%) of the pathologic specimen after formalin fixation which made the specimen appear to be a lower tumor stage.

Patients who presented with advanced-stage (stage IV) disease had a worse prognosis than those with early stages (stage I and II). Patients with advanced-stage disease are more likely to have positive margins, positive metastatic nodes and numerous medical comorbidities. Surgery itself is more complicated for these patients, and motality is potentially higher ${ }^{27}$.

According to the literature, cervical lymph node metastasis is the strongest independent prognostic factor in $\mathrm{OSCC}^{3}$. When neck node metastasis occurs, the cure rate declines by approximately $50 \%{ }^{28}$. In our study, regional lymph node me- 
tastasis was significantly associated with poor outcome. The status of the cervical lymph nodes has been recognized as the single most important factor influencing survival ${ }^{9}$. Nodal disease can decrease survival rates by $50 \%$ or more ${ }^{29}$. Among our patients, those without nodal metastasis (N0) showed a higher survival rate than patients with nodal metastasis (N1 and $\mathrm{N} 2 \mathrm{~b}$ ).

In our study, there was no significant association with smoking and drinking habits. This may be associated with sex difference. Even though our study did not show a significant difference of survival between sexes, there were twice as many male patients than female patients (male:female $=45: 22$ ). None of the female patients were smokers, but 35 of the 45 male patients were smokers $(77.8 \%)$. This suggests that smoking is related to the occurrence of OSCC in male patients. Previous studies have also mentioned that smoking and alcohol use are the two main risk factors for oral $\mathrm{SCC}^{30}$. The occurrence in women might be associated with human papilloma virus (HPV). HPV is an independent risk factor for development of OSCC. In a previous study, HPV DNA was found in $17.5 \%$ of lesion samples from patients with OSCC $^{31}$.

Zelefsky et al. ${ }^{32}$ evaluated the relationship of anatomic site with the treatment outcome of patients with advancedstage oral cavity cancers that were treated with surgery and radiotherapy between 1975 and 1985. The anatomic site had a significant relationship with treatment outcome. Some studies have reported that the increased risk of nodal metastasis in OSCC is dependent on the location of the primary tumor (from the lips to the oropharynx $)^{6,15,16}$. However, Kim et al. ${ }^{33}$ proposed that little difference is found based on anatomic site alone. In our study, patients with cancer at the floor of mouth showed significantly better prognosis than patients with cancer at the maxilla and retromolar trigone. However, the stages of the floor of mouth (FOM) OSCC were stage I and II $(n=7)$ and stage IV $(n=2)$. Two patients with stage IV disease died of their disease. Early-stage cancer in the FOM showed a better prognosis than other sites. Regarding the value of histologic grading for OSCC, studies have shown that poorly differentiated tumors have more metastases than well differentiated counterparts ${ }^{34}$. Also, poorly differentiated tumors were associated with a higher rate of positive margins ${ }^{27}$. According to our results, however, there was no significant difference between the well and moderately differentiated groups. As mentioned above, there was only one patient whose biopsy result was poorly differentiated. Because of a small sample size, it was difficult to conduct histologic grading and make comparisons with other samples. A larger sample size is needed in future studies.

Sixty-two patients showed no cancer cell-positive margins after final pathologic examination. Among the 19 patients who died of local and regional recurrence, five patients had margin-positive tumors even though a negative margin was observed in the frozen section taken during surgery. All patients with positive margins received radiotherapy; however, the adjunctive therapy was ineffective. Fourteen patients showed local or regional recurrence even though a clear resection margin was obtained during the surgery. Because it is impractical to examine the whole margin, there is always a possibility of focal invasion of OSCC. The surgical margin should be carefully determined with clinical and radiological examination.

There are other factors that affect the prognosis and survival of OSCC. Tumor thickness and depth of invasion are known as critical prognostic indicators for upper aero-digestive neoplasm, especially regional metastasis ${ }^{32,35-40}$. The depth of invasion indicates the extent of growth into tissues below the epithelial surface. Thickness is a direct measurement of the vertical volume of the tumor. Many studies imply that the thickness of the tumor is an important predictor of local recurrence ${ }^{35-37}$.

The surgeon-related factor is also known to affect the survival of OSCC; however, it is not easy to evaluate the experience of the surgeon. Our results showed favorable survival rates compared to other studies. Surgeon's skills, facility of the hospital, and nursing in the intensive care unit are critical to survival and postoperative morbidity.

The limitations of the study include a small sample size and retrospective study design. Additional prospective multicenter studies are needed to confirm the findings of the present study.

\section{Conclusion}

OSCC has a poor prognosis, with an OS of $64.2 \%$ and a DSS of $71.6 \%$. Patients with advanced TNM stage cancer showed a lower survival rate than patients with early-stage disease. Patients with lymph node metastasis showed a lower survival rate compared with patients without lymph node metastasis. Other clinical and pathologic factors did not show any significant differences in survival rate in our study. However, a large-scale study will be required in the future to confirm our findings. Patients with stages I and II OSCC showed excellent survival results in this study. 


\section{ORCID}

Yookyeong Carolyn Sim, https://orcid.org/0000-00031568-6247

Jong-Hyun Hwang, https://orcid.org/0000-0003-3392$128 X$

Kang-Min Ahn, https://orcid.org/0000-0003-1215-5643

\section{Authors' Contributions}

Y.C.S. and J.H.H. contributed equally as a first author to perform study, data collection and analysis. K.M.A. operated all the patients and collected patients; data and designed study. All authors read and approved the finsal manuscript.

\section{Ethics Approval and Consent to Participate}

The Institutional Review Board from Asan Medical Center issued an exemption from approval to this study, because we collected existing data in such a manner that the subjects could not be identified.

\section{Conflict of Interest}

No potential conflict of interest relevant to this article was reported.

\section{References}

1. Moore SR, Johnson NW, Pierce AM, Wilson DF. The epidemiology of tongue cancer: a review of global incidence. Oral Dis 2000;6:75-84

2. Johnson NW. Orofacial neoplasms: global epidemiology, risk factors and recommendations for research. Int Dent J 1991;41:365-75.

3. Kim BG, Kim JH, Kim MI, Han JJ, Jung S, Kook MS, et al. Retrospective study on factors affecting the prognosis in oral cancer patients who underwent surgical treatment only. Maxillofac Plast Reconstr Surg 2016;38:3.

4. Madani AH, Dikshit M, Bhaduri D, Aghamolaei T, Moosavy SH, Azarpaykan A. Interaction of alcohol use and specific types of smoking on the development of oral cancer. Int J High Risk Behav Addict 2014;3:e12120.

5. Shiboski CH, Schmidt BL, Jordan RC. Tongue and tonsil carcinoma: increasing trends in the U.S. population ages 20-44 years. Cancer 2005;103:1843-9.

6. Kademani D, Bell RB, Bagheri S, Holmgren E, Dierks E, Potter B, et al. Prognostic factors in intraoral squamous cell carcinoma: the influence of histologic grade. J Oral Maxillofac Surg 2005;63:1599-605.

7. Rogers SN, Brown JS, Woolgar JA, Lowe D, Magennis P, Shaw $\mathrm{RJ}$, et al. Survival following primary surgery for oral cancer. Oral Oncol 2009;45:201-11.

8. Geum DH, Roh YC, Yoon SY, Kim HG, Lee JH, Song JM, et al. The impact factors on 5-year survival rate in patients operated with oral cancer. J Korean Assoc Oral Maxillofac Surg 2013;39:207-16.

9. Hwang DS, Park J, Kim UK, Park HR, Kim GC, Ryu MH. Reconstruction of cheek mucosal defect with a buccal fat pad flap in a squamous cell carcinoma patient: a case report and literature review. Maxillofac Plast Reconstr Surg 2018;40:11.

10. Holtmann H, Spalthoff S, Gellrich NC, Handschel J, Lommen J, Kübler NR, et al. Determinants for further wishes for cosmetic and reconstructive interventions in 1652 patients with surgical treated carcinomas of the oral cavity. Maxillofac Plast Reconstr Surg 2017;39:26.

11. Shah JP, Medina JE, Shaha AR, Schantz SP, Marti JR. Cervical lymph node metastasis. Curr Probl Surg 1993;30:1-335.

12. Bloom ND, Spiro RH. Carcinoma of the cheek mucosa. A retrospective analysis. Am J Surg 1980;140:556-9.

13. Kang $\mathrm{S}$, Leem DH. Verrucous carcinoma arising from a previous cystic lesion: a case report. Maxillofac Plast Reconstr Surg 2018;40:31.

14. Shaha AR, Spiro RH, Shah JP, Strong EW. Squamous carcinoma of the floor of the mouth. Am J Surg 1984;148:455-9.

15. Shah JP, Candela FC, Poddar AK. The patterns of cervical lymph node metastases from squamous carcinoma of the oral cavity. Cancer 1990;66:109-13.

16. Shah JP. Patterns of cervical lymph node metastasis from squamous carcinomas of the upper aerodigestive tract. Am J Surg 1990;160:405-9.

17. Lindberg R. Distribution of cervical lymph node metastases from squamous cell carcinoma of the upper respiratory and digestive tracts. Cancer 1972;29:1446-9.

18. Candela FC, Kothari K, Shah JP. Patterns of cervical node metastases from squamous carcinoma of the oropharynx and hypopharynx. Head Neck 1990;12:197-203.

19. De Vicente JC, Recio OR, Pendás SL, López-Arranz JS. Oral squamous cell carcinoma of the mandibular region: a survival study. Head Neck 2001;23:536-43.

20. Park TJ, Kim HJ, Ahn KM. Double-layered collagen graft to the radial forearm free flap donor sites without skin graft. Maxillofac Plast Reconstr Surg 2015;37:45.

21. Warnakulasuriya S, Mak V, Möller H. Oral cancer survival in young people in South East England. Oral Oncol 2007;43:982-6.

22. Sessions DG, Spector GJ, Lenox J, Parriott S, Haughey B, Chao C, et al. Analysis of treatment results for floor-of-mouth cancer. Laryngoscope 2000;110:1764-72.

23. Horner MJ, Ries LAG, Krapcho M, Neyman N, Aminou R, Howlader N, et al. SEER cancer statistics review, 1975-2006 [Internet]. Bethesda (MD): National Cancer Institute [cited 2018 Jan 25]. Available from: https://seer.cancer.gov/archive/csr/1975_2006.

24. Warnakulasuriya S. Global epidemiology of oral and oropharyngeal cancer. Oral Oncol 2009;45:309-16.

25. Redaniel MT, Laudico A, Mirasol-Lumague MR, Gondos A, Pulte $\mathrm{D}$, Mapua C, et al. Cancer survival discrepancies in developed and developing countries: comparisons between the Philippines and the United States. Br J Cancer 2009;100:858-62.

26. Listl S, Jansen L, Stenzinger A, Freier K, Emrich K, Holleczek B, et al. Survival of patients with oral cavity cancer in Germany. PLoS One 2013;8:e53415.

27. Sklenicka S, Gardiner S, Dierks EJ, Potter BE, Bell RB. Survival analysis and risk factors for recurrence in oral squamous cell carcinoma: does surgical salvage affect outcome? J Oral Maxillofac Surg 2010;68:1270-5.

28. Süslü N, Hoşal AŞ, Aslan T, Sözeri B, Dolgun A. Carcinoma of the oral tongue: a case series analysis of prognostic factors and surgical outcomes. J Oral Maxillofac Surg 2013;71:1283-90.

29. Grandi C, Alloisio M, Moglia D, Podrecca S, Sala L, Salvatori P, et al. Prognostic significance of lymphatic spread in head and neck carcinomas: therapeutic implications. Head Neck Surg 1985;8:6773.

30. Johnson NW, Jayasekara P, Amarasinghe AA. Squamous cell car- 
cinoma and precursor lesions of the oral cavity: epidemiology and aetiology. Periodontol 2000 2011;57:19-37.

31. Phusingha $P$, Ekalaksananan T, Vatanasapt $P$, Loyha K, Promthet $\mathrm{S}$, Kongyingyoes B, et al. Human papillomavirus (HPV) infection in a case-control study of oral squamous cell carcinoma and its increasing trend in northeastern Thailand. J Med Virol 2017;89:10961101.

32. Zelefsky MJ, Harrison LB, Fass DE, Armstrong J, Spiro RH, Shah JP, et al. Postoperative radiotherapy for oral cavity cancers: impact of anatomic subsite on treatment outcome. Head Neck 1990; 12:470-5.

33. Kim HJ, Park TJ, Ahn KM. Bisphosphonate-related osteonecrosis of the jaw in metastatic breast cancer patients: a review of 25 cases. Maxillofac Plast Reconstr Surg 2016;38:6.

34. Kurokawa H, Zhang M, Matsumoto S, Yamashita Y, Tomoyose T, Tanaka T, et al. The high prognostic value of the histologic grade at the deep invasive front of tongue squamous cell carcinoma. J Oral Pathol Med 2005;34:329-33.

35. Kim BG, Kim JH, Kim MI, Han JJ, Jung S, Kook MS, et al. Retrospective study on factors affecting the prognosis in oral cancer patients who underwent surgical treatment only. Maxillofac Plast Reconstr Surg 2016;38:3.

36. Mohit-Tabatabai MA, Sobel HJ, Rush BF, Mashberg A. Relation of thickness of floor of mouth stage I and II cancers to regional metastasis. Am J Surg 1986;152:351-3.

37. Jones KR, Lodge-Rigal RD, Reddick RL, Tudor GE, Shockley WW. Prognostic factors in the recurrence of stage I and II squamous cell cancer of the oral cavity. Arch Otolaryngol Head Neck Surg 1992;118:483-5.

38. Fukano H, Matsuura H, Hasegawa Y, Nakamura S. Depth of invasion as a predictive factor for cervical lymph node metastasis in tongue carcinoma. Head Neck 1997;19:205-10.

39. Brown B, Barnes L, Mazariegos J, Taylor F, Johnson J, Wagner RL. Prognostic factors in mobile tongue and floor of mouth carcinoma. Cancer 1989;64:1195-202.

40. Ambrosch P, Kron M, Fischer G, Brinck U. Micrometastases in carcinoma of the upper aerodigestive tract: detection, risk of metastasizing, and prognostic value of depth of invasion. Head Neck 1995;17:473-9. 